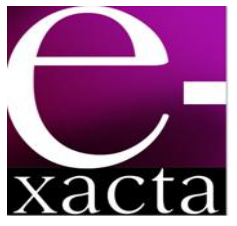

ISSN: 1984-3151

\section{AVALIAÇÃo DO POTENCIAL DE AMOSTRAS DE ASPERGILLUS SSP ISOLADAS DA CAATINGA PARA PRODUÇÃO DE LACASE}

\author{
Tiago Lira de Melo', Marcos Antônio Cavalcanti Luna², Leonor Alves de Oliveira da \\ Silva ${ }^{3}$, Galba Maria de Campos-Takaki ${ }^{4}$, Carlos Alberto Alves da Silva ${ }^{5}$
}

1 Mestrando em Desenvolvimento de Processos Ambientais. Universidade Católica de Pernambuco, Recife, PE. tiagoliramelo@gmail.com.

2 Doutorando do Rede Nordeste de Biotecnologia - RENORBIO, Recife, PE. macluna@bol.com.br.

3 Doutora em Ciências Biológicas, Departamento de Antibióticos, UFPE, Recife, PE. laodls@yahoo.com.br.

4 Doutora em Microbiologia Núcleo de Pesquisas em Ciências Ambientais e Biotecnologia (NPCIAMB), Universidade Católica de Pernambuco, Recife, PE. takaki@unicap.br.

5 Doutor em Biotecnologia. Núcleo de Pesquisas em Ciências Ambientais e Biotecnologia (NPCIAMB), Universidade Católica de Pernambuco, Recife, PE. calves@unicap.br.

Recebido em: 13/03/2015 - Aprovado em: 26/05/2015 - Disponibilizado em: 30/05/2015

RESUMO: Os estudos envolvendo novos micro-organismos produtores de enzimas têm aumentado nas últimas décadas devido à imensa diversidade microbiana existente, principalmente em ambientes como a Caatinga que apresenta uma microbiota pouco conhecida. As lacases são enzimas que apresentam sua atuação sobre uma grande variedade de compostos químicos, tornando-a uma enzima extremamente versátil e com um elevado potencial para ser utilizada em várias aplicações biotecnológicas industriais. Os efluentes agroindustriais, principalmente os da indústria de alimentos, muitas vezes são descartados de maneira incorreta no meio ambiente e apresentam um elevado poder nutricional que poderia ser aproveitado na formulação de meios para produção de inúmeras enzimas lignocelulolíticas. Neste sentido os fungos vêm sendo amplamente utilizados na produção dessas enzimas. Foram realizados estudos de produção de lacase em meio sólido utilizando 6 amostras de Aspergillus ssp isoladas da Caatinga de Pernambuco em diferentes temperaturas $\left(28,37\right.$ e $\left.45^{\circ} \mathrm{C}\right), \mathrm{pH}(5,6,7,8$ e 9) e indutores da enzima (tween 20, ácido tânico e o sulfato de cobre). Após o processo de seleção em meio sólido, foram realizados ensaios de produção através de fermentação submersa utilizando 3 meios diferentes, durante 120 horas, $150 \mathrm{rpm} 28^{\circ} \mathrm{C}$. Os resultados evidenciaram que a amostra SIS 14 apresentou o maior halo de produção da enzima $3,0 \mathrm{~cm}$, na temperatura de $28^{\circ} \mathrm{C}, \mathrm{pH} 6,0$ e o Tween 20 como indutor. No processo de produção através de fermentação submersa foram avaliadas a determinação da atividade enzimática, pH e biomassa em intervalos de 24 horas, durante 5 dias. 0 meio 3 foi o que apresentou a maior atividade enzimática $0,3 \cup L^{-1}$ no período de 96 horas.

PALAVRAS-CHAVE: Fungos filamentosos, Produção enzimas microbianas, Seleção indutores.

ABSTRACT: Studies involving new producers of enzymes microorganisms have increased in recent decades due to the immense existing microbial diversity, especially in environments such as the Caatinga having a little known microbiota. Laccases are enzymes that exhibit its performance on a wide variety of chemical compounds, making it 
an extremely versatile enzyme with a high potential to be used in various industrial biotechnological applications. The agro-industrial effluents, especially the food industry, are often disposed of improperly in the environment and have a high nutritional power that could be used in the media formulation for the production of numerous enzymes lignocellulolytic. In this sense fungi have been widely used in the production of these enzymes. Laccase production studies have been performed on solid media using 6 samples isolated from Aspergillus ssp Caatinga Pernambuco at different temperatures (28, 37 and $\left.45^{\circ} \mathrm{C}\right), \mathrm{pH}(5,6,7,8$ and 9) and inducers of the enzyme (Tween 20, tannic acid and copper sulfate). After the selection process on solid medium, production tests were performed through submerged fermentation using 3 different media, for 120 hours, $150 \mathrm{rpm} 28 \mathrm{oC}$. The results showed that the SIS 14 sample showed the highest enzyme production halo $3.0 \mathrm{~cm}$, at a temperature of $28^{\circ} \mathrm{C}, \mathrm{pH} 6.0$ and Tween 20 as an inducer. In the production process by submerged fermentation were evaluated to determine the enzyme activity, $\mathrm{pH}$ and biomass in 24-hour intervals for 5 days. The media three was the one with the highest enzyme activity $0.3 \cup L^{-1}$ within 96 hours.

KEYWORDS: Filamentous fungi, Microbial enzymes production, Selection inductors.

\section{INTRODUÇÃo}

Nos últimos anos, as enzimas têm sido bastante utilizadas nos diversos setores industriais, pois atuam como catalisadores de diversas reações químicas em várias áreas e são produzidas por diversos gêneros de micro-organismos através de processos fermentativos (HASAN; SHAH; HAMEED, 2006; KUHAD; GUPTA; SINGH, 2011; JUTURU; WU, 2012; GOPINATH, et al., 2015).

As lacases (EC 1.10.3.2) são enzimas denominadas de polifenol oxidases, sendo encontrada em plantas, insetos, bactérias e fungos filamentosos (ARORA, GILL, 2000; SHEKHER, et al., 2011; GUPTA, et al., 2014; EL-BATAL, et al., 2015).

Lacases fúngicas são glicoproteínas de 520-550 aminoácidos que contêm quatro íons cobre $(\mathrm{Cu})$ dispostos em três sítios de ligação, onde cada íon desempenha um papel importante na reação catalítica que ocorre pela oxidação de um substrato fenólico, enquanto oxigênio molecular é reduzido à água (LEITNER et al., 2002; GIARDINA, et al., 2010; AYDINOĞLU; SARGIN, 2013; MEKMOUCHE, et al., 2014; GIARDINA, SANNIA, 2015).

Esse grupo de enzimas se caracteriza por apresentar uma baixa especificidade por substratos, permitindo assim sua atuação sobre uma grande variedade de compostos químicos, o que a torna uma enzima extremamente versátil e com um elevado potencial para ser utilizada em várias aplicações biotecnológicas industriais: processos da indústria de papel e celulose, têxtil, cosmética, detoxificação de esgotos, processos de síntese inorgânica, degradação de xenobióticos, biorremediação, produção de detergentes (MINUSSI; PASTORE; DURÁN, 2002; COUTO; TOCA-HERRERA, 2007; MADHAVI; LELE, 2009; KUDANGA; LE ROES-HILL, 2014; GIARDINA; SANNIA, 2015).

Estudos realizados mostram que a produção de lacase pode ser estimulada consideravelmente pela presença de diversos tipos de indutores, principalmente compostos fenólicos relacionados com a lignina ou com derivados dela, compostos compostos surfactantes não iônicos, como o Tween 20 , e derivados de cobre que possam se ligar a parte estrutural da enzima aumentando assim seu produção por processos fermentativos. (BALDRIAN, GABRIEL, 2002; LOERA et al., 2006).

O gênero Aspergillus tem se destacado como um excelente produtor de metabólitos secundários de interesse industrial e ambiental (BERKA, DUNNCOLEMAN, WARD, 1992; WARD et al., 2005; LOTFY; GHANEM; EL-HELOW, 2007; MATA-GOMEZ et al., 2009; DHILLON et al., 2012; GOSWAMI et al., 2012; CHAVAN; DESHPANDE, 2013; PATRO et al., 2014; SHIVANNA, VENKATESWARAN, 2014). 
Este trabalho teve como objetivos a seleção de amostras de Aspergillus ssp isolados da Caatinga de Pernambuco, com potencial produção de lacase em meio sólido, seleção de indutores e de meios de produção através de fermentação submersa.

\section{MATERIAIS E MÉTODOS}

\subsection{MICRO-ORGANISMOS}

Foram utilizadas 6 amostras do gênero Aspergillus ssp $\operatorname{UCP}(09,10,11,14,15$ e 16), isoladas no semi-árido de Pernambuco com a identificação e catalogadas no Banco de Culturas da Universidade Católica de Pernambuco (UNICAP), localizado no Núcleo de Pesquisas em Ciências Ambientais (NPCIAMB) registradas no World Federatcn Culture for CollectionWFCC. As culturas foram mantidas em Meio Sabouraud Dextrose Agar (SDA) incubadas para crescimento durante 120 horas, a $28 \stackrel{\circ}{\circ} \mathrm{C}, \mathrm{pH} 7,0$.

\subsection{Produção de LACASE em Meio sólido}

Para detecção e produção da lacase em meio sólido foi utilizado o meio descrito por Olga et al.,(1998); contendo $\left(\mathrm{g} \mathrm{L}^{-1}\right): 3,0$ de peptona, 10,0 de glicose, 0,6 de $\mathrm{KH}_{2} \mathrm{PO} 4,0,001$ de $\mathrm{ZnSO}_{4}, 0,4$ de $\mathrm{K}_{2} \mathrm{HPO}_{4}, 0,0005$ de $\mathrm{FeSO}_{4}$, 0,05 de $\mathrm{MnSO}_{4}$, 0,5 de MgSO4, 20,0 de

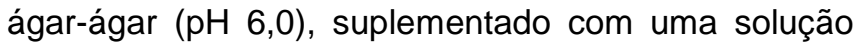
de $0,02 \%$ guaiacol.

Para realização dos ensaios foi preparada uma solução espórica cuja concentração foi de $1 \times 10^{7}$ esporos $\mathrm{mL}^{-1}$ de Aspergillus ssp. Foram preparadas placas contendo o meio de detecção, e após a solidificação, um furo de $0,8 \mathrm{~cm}$ de diâmetro no meio da placa.

Alíquotas de $100 \mu \mathrm{L}$ da suspensão espórica foram inoculadas e as placas incubadas em estufas com diferentes temperaturas $28{ }^{\circ} \mathrm{C}, 37 \stackrel{\circ}{\circ} \mathrm{C}$ e $45 \stackrel{\circ}{\circ} \mathrm{C}$, com diferentes valores de $\mathrm{pH}: 5,6,7,8$ e 9, durante 7 dias, sendo acompanhadas diariamente.

As alterações no crescimento e a formação de halo transparente característico ao redor da cultura indicam a produção e excreção da enzima pelos microorganismos testados. Todos os experimentos foram realizados em triplicata.

\subsection{SELEÇÃo de INDUTORES}

Foram realizados estudos visando a substituição do guaicol como indutor, devido a sua elevada toxicidade, nos ensaios em meio sólido com outros indutores de produção da lacase descritos pela literatura, utilizando a mesma concentração do guaicol descrita na literatura $(0,02 \%)$.

Os seguintes indutores foram testados: $\mathrm{CuSO}_{4} \cdot 5 \mathrm{H}_{2} \mathrm{O}$ (JAOUANI et al., 2005), ácido tânico (SOUZA et al., 2004) e tween 20 (POINTING et al., 2000).

\subsection{Seleção de meios de produção de LACASE EM FERMENTAÇÃO SUBMERSA}

Após a seleção da melhor amostra de Aspergillus sp, produtora de lacase, da temperatura, $\mathrm{pH}$ e do indutor foram iniciados os testes de produção da enzima por fermentação submersa.

Foram testados ensaios de produção da enzima utilizando três meios de produção:

Meio 1: descrito por Coll et al., (1993); contendo $\left(\mathrm{g} \mathrm{L}^{-1}\right): 10$ de glicose , 1,0 de asparagina, $0,50 \mathrm{de}$ extrato de levedura, 0,50 de $\mathrm{K}_{2} \mathrm{HPO}_{4}, 1,00$ de $\mathrm{MgSO}_{4} .7 \mathrm{H}_{2} \mathrm{O}, 0,01$ de $\mathrm{FeSO}_{4} .7 \mathrm{H}_{2} \mathrm{O} ; \mathrm{pH} 6,0$.

Meio 2: descrito por Kluczek-Turpeinen et al., (2003); $\left(\mathrm{g} \mathrm{L}^{-1}\right): 3,0$ de $\mathrm{NaNO}_{3}, 1,0$ de $\mathrm{Na}_{2} \mathrm{HPO}_{4}, 5,0$ de $\mathrm{MgSO}_{4} 7 \mathrm{H}_{2} \mathrm{O}, 0,5$ de $\mathrm{KCl}, 0,01$ de $\mathrm{FeSO}_{4} \cdot 7 \mathrm{H}_{2} \mathrm{O}$, 0,005 de extrato de levedura, 5 de glicose; $\mathrm{pH} 6,0$.

e-xacta, Belo Horizonte, v. 8, n. 1, p. 67-75. (2015). Editora UNIBH. Disponível em: www.unibh.br/revistas/exacta/ 
Meio 3: descrito por Olga et al., (1998); contendo $\left(\mathrm{g} \mathrm{L}^{-1}\right): 10$ de glicose, 0,6 de $\mathrm{KH}_{2} \mathrm{PO}_{4}, 0,001$ de $\mathrm{ZnSO}_{4}$, 0,4 de $\mathrm{K}_{2} \mathrm{HPO}_{4}, 0,0005$ de $\mathrm{FeSO}_{4}, 0,05$ de $\mathrm{MnSO}_{4}$, 0,5 de $\mathrm{MgSO}_{4}, \mathrm{pH} 6,0$.

\subsection{DeterminaÇÃo dA BIOMASSA}

A biomassa microbiana foi determinada através de gravimetria. O peso seco foi estimado a partir de amostras de $50 \mathrm{~mL}$ coletadas durante todo o processo de produção.

\subsection{DeTECÇão dA ATIVIDADE ENZIMÁTICA}

A atividade de lacase foi determinada por método espectrofotométrico indireto através da metodologia de Buswell, Cai e Chang (1995) utilizado 2,2'-azino-bis etilbentiazoline (ABTS) em mistura de reação de $1 \mathrm{~mL}$ contendo $0,3 \mathrm{~mL}$ de tampão acetato de sódio $0,1 \mathrm{~mol} \mathrm{~L}^{-1}$ e $0,6 \mathrm{~mL}$ de extrato enzimático.

A mistura da reação foi inoculada, por 5 minutos, a $37 \stackrel{\circ}{ } \mathrm{C}$ e a oxidação do ABTS foi medida através do aumento da absorbância a $420 \mathrm{~nm}$. O branco foi realizado com todos os componentes da mistura da reação, substituindo o extrato enzimático pelo meio de produção sem inoculação.

Uma unidade de atividade enzimática específica foi definida como a quantidade de enzima capaz de oxidar $1 \mu \mathrm{mol}$ de ABTS por minuto $\left(\varepsilon_{420}=3,6 \times 10^{4} \mathrm{~mol}^{-1}\right.$ $\mathrm{L} \mathrm{cm}^{-1}$ ) por mg de proteína.

\subsection{CÁlCULO DA ATIVIDADE ENZIMÁTICA}

A atividade cinética da produção da lacase foi calculada através a Eq. 1, descrita por Aguiar Filho (2008).

$$
U I / L=\frac{\Delta A b s}{\varepsilon \times R \times t} \times 10^{6}
$$

Onde,

Abs = absorbância;

$\varepsilon=$ coeficiente de absorção molar;

$\mathrm{R}$ = quantidade de solução da amostra;

$\mathrm{t}=$ tempo de reação em minutos;

$\mathrm{UI} \mathrm{L}^{-1}=$ Unidade Internacional, onde internacional significa $\mu \mathrm{mol} \mathrm{min}^{-1}$.

\subsection{DETERMINAÇÃo DE PROTEÍNAS TOTAIS}

A dosagem de proteínas foi realizada de acordo com o método descrito por Bradford (1976), que consiste em reação com $0,2 \mathrm{~mL}$ de amostra e $0,8 \mathrm{~mL}$ de reagente de Bradford sob agitação.

A leitura foi realizada em espectrofotômetro a $595 \mathrm{~nm}$. A concentração de proteínas foi obtida pela dosagem em curva de padrão de albumina de soro bovino (BSA).

\section{RESUltados E discussões}

\subsection{Seleção de amostras produtoras de LACASE EM MEIO SÓLIDO}

Os resultados obtidos nos ensaios de seleção de amostras produtoras de lacase estão descritos na TAB. 1. As suspensões espóricas foram inoculadas em poços nas placas de Petri contendo o meio padrão de detecção da lacase em meio sólido. As placas foram incubadas em estufas diferentes temperaturas $\left(28^{\circ} \mathrm{C}, 37^{\circ} \mathrm{C}, 45^{\circ} \mathrm{C}\right)$ e diferentes valores de $\mathrm{pH}$, durante 120 horas. 
Tabela 1

Detecção da atividade enzimática das amostras de Aspergillus sp isoladas no semi-árido de Pernambuco com diferentes indutores (Tween 20, ácido tânico, sulfato de cobre heptahidratado)

\begin{tabular}{|c|c|c|c|c|c|}
\hline $\begin{array}{c}\text { Micro- } \\
\text { organismos }\end{array}$ & $\circ \mathrm{C}$ & Tempo & $\begin{array}{c}\text { Tween } \\
20\end{array}$ & $\begin{array}{l}\text { Ácido } \\
\text { Tânico }\end{array}$ & $\begin{array}{c}\text { Sulfato } \\
\text { de } \\
\text { cobre }\end{array}$ \\
\hline & 28 & 120 & 2,6 & 2,5 & 2,5 \\
\hline \multirow[t]{2}{*}{ SIS 09} & 37 & 120 & 2,2 & 2,1 & 2,0 \\
\hline & 28 & 120 & 2,4 & 2,5 & 2,5 \\
\hline \multirow[t]{2}{*}{ SIS 10} & 37 & 120 & 2,4 & 2,0 & 2,0 \\
\hline & 28 & 120 & 2,4 & 2,5 & 1,5 \\
\hline \multirow[t]{2}{*}{ SIS 11} & 37 & 120 & 2,0 & 2,0 & 2,0 \\
\hline & 28 & 120 & 3,0 & 2,7 & 2,0 \\
\hline \multirow[t]{2}{*}{ SIS 14} & 37 & 120 & 2,5 & 2,3 & 2,0 \\
\hline & 28 & 120 & 2,5 & 2,4 & 1,5 \\
\hline \multirow[t]{2}{*}{ SIS 15} & 37 & 120 & 2,3 & 2,0 & 1,7 \\
\hline & 28 & 120 & 2,5 & 2,3 & 1,5 \\
\hline SIS 16 & 37 & 120 & 2,4 & 2,0 & 1,6 \\
\hline
\end{tabular}

Verifica-se que em todos os ensaios realizados com os diferentes indutores da lacase nas diferentes amostras testadas houve produção da enzima testada, porém não houve a formação do halo característico da enzima em nenhuma amostra testada na temperatura de $45^{\circ} \mathrm{C}$.

Os valores dos halos obtidos nas temperaturas de $37{ }^{\circ} \mathrm{C}$, foram considerados menores que os obtidos nos mesmos ensaios realizados com a temperatura de $28^{\circ} \mathrm{C}$, mesmo com a utilização de diferentes indutores.

Dentre as amostras testadas, a denominada de SIS 14 apresentou o maior halo de produção da lacase nos ensaios realizados, cujo valor foi de $3,0 \mathrm{~cm}$, no meio que continha 0 Tween 20 como indutor, na temperatura de $28 \stackrel{\circ}{\mathrm{C}}$.
Pozdnyakova et al., (2004), descrevem que a presença de surfactantes não iônicos, como o Tween 20, têm sido utilizados para aumentar a viabilidade das reações entre as enzimas e seus respectivos substratos, aumentando assim sua produção.

Observa-se que os meios que continham o Tween 20 como indutor apresentaram as maiores produções de lacase, quando comparados aos demais meios com indutores diferentes utilizados (ácido tânico e $\mathrm{CuSO}_{4} \cdot 5 \mathrm{H}_{2} \mathrm{O}$ ). Pointing et al., (2000), descreveram que a produção de lacase pode ser estimulada ou aumentada através da adição de surfactantes não iônicos como o Tween-20.

A FIG. 1 demonstra a formação do halo característico da enzima, no meio contendo Tween 20 como indutor nos ensaios realizados. No lado direito, encontra-se uma placa que não apresenta a formação do referido halo, sendo considerado resultado negativo.

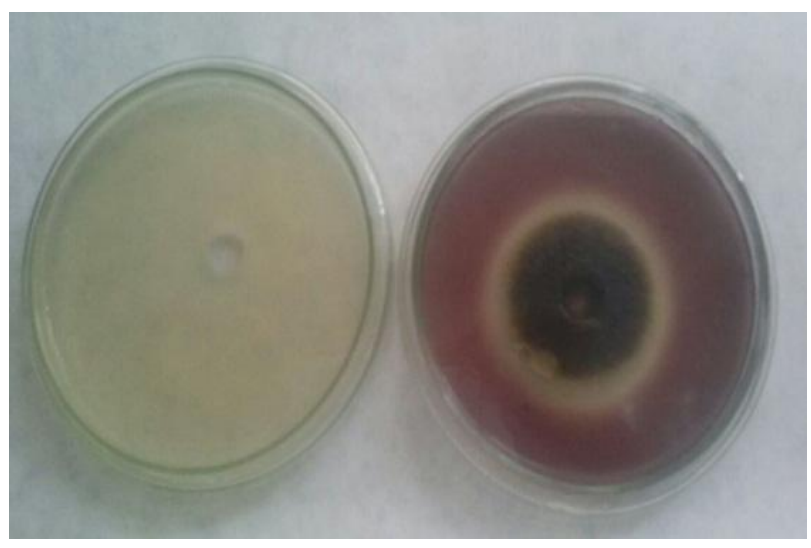

Figura 1 - Placas de Petri com a formação do halo característico da lacase em 120 horas (UCP 14-28 ํ).

Giese et al. (2004) observaram que adição desse mesmo surfactante ao meio de produção, o Tween 20, aumentou em quase 3 vezes mais a produção de lacases através do Pycnoporus sanguineu. 


\subsection{Produção de lacase através de FERMENTAÇÃO SUBMERSA}

A amostra selecionada na detecção de lacase em meio sólido, foi inoculada nos meios de produção através de fermentação submersa descritos por Coll et al., (1993), Kluczek-Turpeinen et al., (2003); e Olga et al., (1998). Sendo os experimentos realizados em Shaker rotacional a $150 \mathrm{rpm}$ a $28{ }^{\circ} \mathrm{C}$, durante 120 horas.

Os resultados obtidos da determinação enzimática estão descritos na FIG. 2. Verifica-se a maior produção enzimática ocorreu no período de 96 horas nos diferentes meios testados e observa-se um declínio da atividade enzimática após 120 horas de produção em todos os três meios testados.

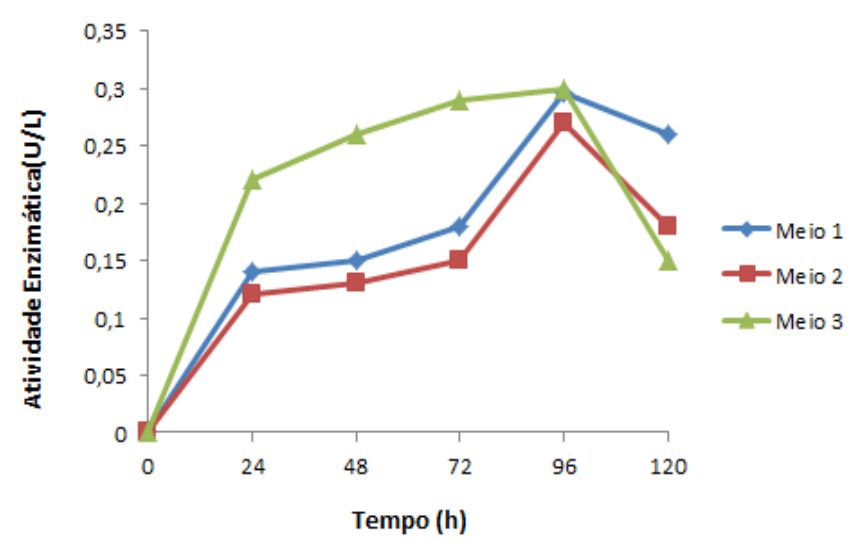

Figura 2 - Variação da atividade da lacase em meiosde produção através da amostra SIS 14 Aspergillus sp, $150 \mathrm{rpm}, 28 \stackrel{\circ}{\circ}$.

Buddolla (2008), utilizando o mesmo meio denominado de 3 em seus experimentos de produção de lacase, obteviveram-se bons resultados na produção da enzima utilizando amostras de Stereum ostrea e Phanerochaete chrysosporium.

$\mathrm{Na}$ TAB. 2 encontram-se os valores obtidos determinação da atividade da lacase produzida em diferentes meios utilizando a amostra SIS 14 e também os valores das proteínas totais obtidas.
Verifica-se que atividade enzimática foi detectada em todas as amostras coletadas durante todo processo fermentativo nos diferentes meios testados, mesmo após as primeiras 24 horas de ensaios de produção, apresentando um conteúdo de proteínas totais.

A maior atividade enzimática foi detectada no meio denominado de 3 , obtendo uma maior atividade enzimática da lacase em $96 \mathrm{~h}$ de $0,3 \mathrm{U} \mathrm{L}^{-1}$, com uma quantidade de proteínas totais de $0,144 \mathrm{mg} \mathrm{mL}^{-1}$. A menor atividade foi observada no meio denominado de 2 em $24 \mathrm{~h}$, cuja atividade foi de $0,12 \mathrm{U} \mathrm{L}^{-1}$, com uma quantidade de proteína de $0,197 \mathrm{mg} \mathrm{mL}^{-1}$.

\section{Tabela 1}

Determinação da atividade da lacase $\left(U L^{-1}\right)$ e das proteínas totais $\left(\mathrm{mg} \mathrm{mL}^{-1}\right)$ durante a produção de lacase pela amostra SIS 14, em diferentes meios de produção, $150 \mathrm{rpm}, 28^{\circ} \mathrm{C}, 120$ horas

\begin{tabular}{ccccccc}
\hline Tempo & $\begin{array}{c}\mathrm{M} 1 \\
\left(\mathrm{U} \mathrm{L}^{-1}\right)\end{array}$ & $\begin{array}{c}\mathrm{P} 1 \\
\left(\mathrm{mg} \mathrm{mL}^{-1}\right)\end{array}$ & $\begin{array}{c}\mathrm{M} 2 \\
\left(\mathrm{UL}^{-1}\right)\end{array}$ & $\begin{array}{c}\mathrm{P} 2 \\
\left(\mathrm{mg} \mathrm{mL}^{-1}\right)\end{array}$ & $\begin{array}{c}\mathrm{M} 3 \\
\left(\mathrm{UL} \mathrm{L}^{-1}\right)\end{array}$ & $\begin{array}{c}\mathrm{P3} \\
\left(\mathrm{mg} \mathrm{mL}^{-1}\right)\end{array}$ \\
\hline $\mathbf{2 4}$ & 0,14 & 0,159 & 0,12 & 0,197 & 0,22 & 0,288 \\
$\mathbf{4 8}$ & 0,15 & 0,151 & 0,13 & 0,235 & 0,26 & 0,197 \\
$\mathbf{7 2}$ & 0,18 & 0,508 & 0,15 & 0,159 & 0,29 & 0,258 \\
$\mathbf{9 6}$ & 0,28 & 0,258 & 0,27 & 0,258 & $\mathbf{0 , 3 0}$ & $\mathbf{0 , 1 4 4}$ \\
$\mathbf{1 2 0}$ & 0,26 & 0,25 & 0,18 & 0,230 & 0,15 & 0,258
\end{tabular}

M1 - meio 1, P1 -proteína total meio 1, M2-meio2, P2-proteína total meio 2, M3 - meio 3, P3 -proteína total meio 3.

\subsection{DETERMINAÇÃO DA BIOMASSA E VARIAÇÃO $\mathrm{DO} \mathrm{PH}$}

A produção de biomassa foi detectada em todas as amostras coletadas durante as $120 \mathrm{~h}$ do processo fermentativo. Na FIG. 3 encontram-se os resultados obtidos nos diferentes meios testados para produção da lacase. 


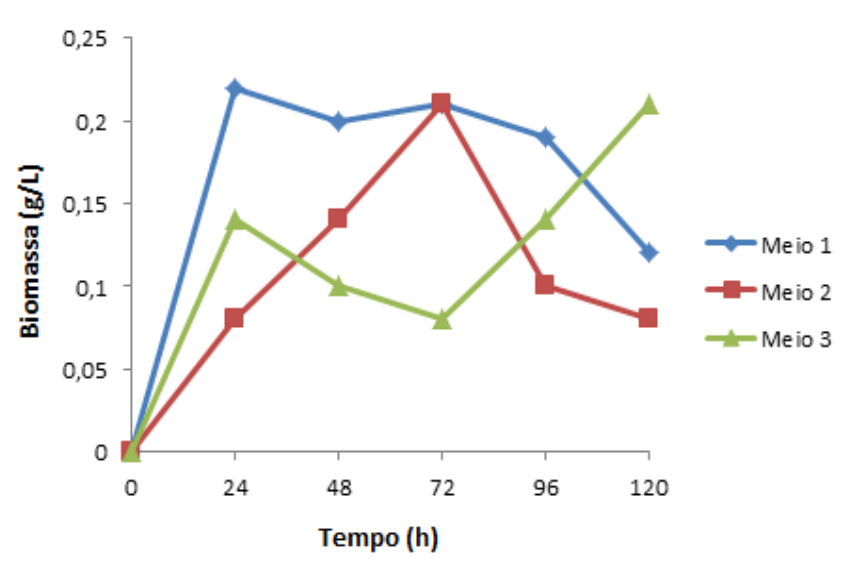

Figura 3 - Determinação da biomassa produzida pela amostra SIS 14 nos diferentes meios de produção de lacase, $150 \mathrm{rpm}, 28^{\circ} \mathrm{C}, 120 \mathrm{~h}$.

A maior quantidade de biomassa produzida foi detectada no meio denominado de $3\left(0,21 \mathrm{~g} \mathrm{~L}^{-1}\right)$ em 120 horas .Verifica-se também que houve uma fase lag mais acentuada no meio 1 e uma considerada mais discreta no meio 2, ambas detectadas nas primeiras 24 horas de fermentação.

Os valores de $\mathrm{pH}$ obtidos nas 3 fermentações, utilizando diferentes meios de produção enzimático, estão descritos na FIG. 4. Os valores obtidos demonstraram que os valores de $\mathrm{pH}$ no meio 1 , apresentaram um aumento na faixa de 5,0 a 6,4 , o que caracteriza um potencial hidrogeniônico com valores próximos da neutralidade.

As menores oscilações de $\mathrm{pH}$ foram verificadas no meio 2, que apresentou um discreto aumento de escala, variando na faixa neutra entre 7,0 e 7,25. 0 meio 3 apresentou variações bruscas dos valores de $\mathrm{pH}$, indicando o consumo dos substratos no meio.

Giese et al. (2004) descrevem que os valores do $\mathrm{pH}$ inicial e final não foram alterados significativamente quando utilizaram meios contendo em sua composição indutores como os Tween 60, 40 e 20.

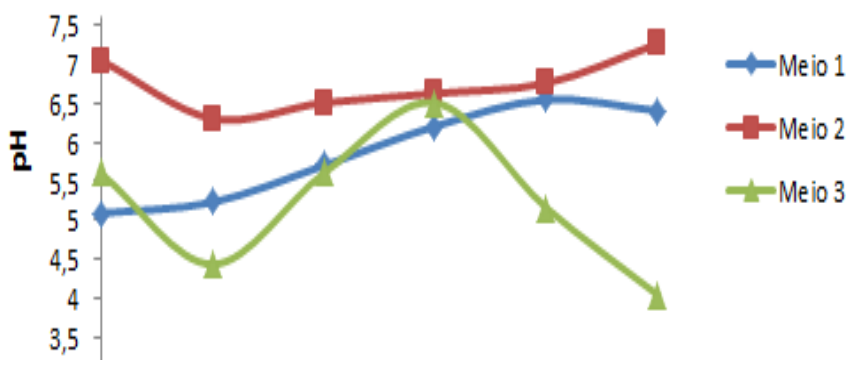

Figura 4 - Determinação do pH pela amostra SIS 14 nos diferentes meios de produção de lacase, $150 \mathrm{rpm}, 28 \stackrel{\circ}{\circ} \mathrm{C}, 120 \mathrm{~h}$.

Buddolla et al. (2008), obtiveram um valor de $\mathrm{pH} 3,61$ quando utilizaram culturas de Phanerochaete chrysosporium e valor de 4,72 quando utilizaram amostras de Stereum ostrea em 94 horas de incubação, utilizando o mesmo meio de produção descrito por Olga et al., (1998).

\section{Considerações finAIS}

A utilização de micro-organismos isolados de ambientes pouco estudados como a Caatinga para produção de enzimas microbianas tem revelado a presença de uma grande diversidade biotecnológica, desse ambiente ainda pouco conhecido e descrito na literatura.

A utilização de diferentes indutores nos meios de detecção revelou que a lacase pode ser estimulada por compostos químicos que apresentam um baixo grau de toxicidade.

Verifica-se a habilidade de fungos filamentosos, principalmente do gênero Aspergillus através de estudos envolvendo a seleção e a produção de metabólitos secundários de alto valor agregado tem sido realizada com eficiência, revelando assim novos produtores de enzimas microbianas. 


\section{AGRADECIMENTOS}

Os autores agradecem ao Projeto SISBIOTA-CNPq, FACEPE e UNICAP pelo suporte financeiro para realização deste trabalho, e ao Núcleo de Pesquisas em Ciências Ambientais e Biotecnologia (NPCIAMB) da Universidade Católica de Pernambuco (UNICAP), pela infra-estrutura para execução de toda parte experimental.

\section{REFERÊNCIAS}

AGUIAR FILHO, J.M.M. Análise enzimática de fungos lignocelulolíticos cultivados em linhaça $e$ bagaço de cana-de-açúcar. Dissertação de Mestrado em Agronomia. Escola Superior de Agricultura "Luiz de Queiroz". Universidade de São Paulo, 80p., 2008.

ARORA, D. S., GILL, P. K. Laccase production by some white rot fungi under different nutritional conditions. Bioresource Technology, v. 73, n. 3, p. 283-285, 2000.

ARORA, D. S., SHARMA, R. K. Ligninolytic Fungal Laccases and Their Biotechnological Applications. Applied Biochemistry and Biotechnology, v.160, p.1760-88, 2009.

AYDINOĞLU, T.; SARGIN, S. Production of laccase from Trametes versicolor by solid-state fermentation using olive leaves as a phenolic substrate. Bioprocess and biosystems engineering, v. $36, n$. 2, p. 215-222, 2013.

BALDRIAN P, GABRIEL, J. Copper and cadmium increase laccase activity in Pleurotus ostreatus. FEMS Microbiology Letters, v.206, p. 69-74, 2002.

BERKA, R.M.; DUNN-COLEMAN, N.; WARD, M.Industrial enzymes from Aspergillus species. Biotechnology, v.23, p.155-202, 1992.

BRADFORD, M.M. A rapid and sensitive method for the quantification of micrograms quantities of protein utilizing the principle of protein-dye binding, Anal. Biochem., v.72, p. 248-254, 1976.

BUDDOLLA, et al. Screening and assessment of laccase producing fungi isolated from different environmental samples. African Journal of Biotechnology v. 7, n.8, p.1129-1133, 2008.

BUSWELL, J.A.; CAI, Y. J.; CHANG. S. T. Effect of nutrient nitrogen and manganese on manganese peroxidase and laccase production by Lentinula (Lentinus) edodes. FEMS Microbiology Letters, v.128, n. 15, p. 81-87, 1995.
CHAVAN, S. B.; DESHPANDE, M. V. Chitinolytic enzymes: An appraisal as a product of commercial potential. Biotechnology Progress, v.29, n.4, p. 833846, 2013.

COLL P.M. et al. Purification and characterization phenoloxidase (Laccase) from the lignin-degrading basidiomycete PM1 (CECT 2971). Appl. Environ. Microbiol. v.59, p.2607-2613, 1993.

COUTO, S. R.; TOCA-HERRERA, J. L. Laccase production at reactor scale by filamentous fungi. Biotechnology Advances, v. 25, p. 558-569, 2007.

DHILLON, G. S. et al. Biotechnological potential of industrial wastes for economical citric acid bioproduction by Aspergillus niger through submerged fermentation. International Journal of Food Science and Technology, v.47, p.542-548, 2012.

EL-BATAL, A. I. et al. Laccase production by Pleurotus ostreatus and its application in synthesis of gold nanoparticles. Biotechnology Reports, v. 5, p. 31-39, 2015.

GIARDINA P. et al. Laccases: a never-ending story, Cell. Mol. Life Sci., v.67, p. 369-385, 2010.

GIARDINA, P., SANNIA, G. Laccases: old enzymes with a promising future. Cellular and Molecular Life Sciences, p. 1-2, 2015.

GIESE et al. Influência de Tween na produção de lacases constitutivas e indutivas pelo Botryosphaeria sp. Acta Scientiarum. Biological Sciences, v. 26, n. 4, p. $463-470,2004$

GOPINATH, S.C.B et al. Biotechnological Aspects and Perspective of Microbial Keratinase Production. BioMed Research International, Article ID 140726, p. $1-11,2015$.

GOSWAMI, S. et al. A review on production of Techinocandins by Aspergillus sp. J. Biochem Tech. v.4, n.1, p. 568-575, 2012. 
GUPTA, V. et al. Production of thermo-alkali-stable laccase and xylanase by co-culturing of Bacillus sp. and B. halodurans for biobleaching of kraft pulp and deinking of waste paper. Bioprocess and Biosystems Engineering, p. 1-10, 2014.

HASAN, F., SHAH, A. A., HAMEED, A. Industrial applications of microbial lipases. Enzyme and Microbial Technology, v. 39, n. 2, p. 235-251, 2006.

JAOUANI, A.;GUILLÉN, F.;PENNINCKX, M. J.; MARTÍNEZ, A.T. \& MARTÍNEZ, M. J. Role of Pycnoporus coccineus laccase in the degradation of aromatic compounds in olive oil mil wastewater Enzime and Microbial Technology, v.36, p.4 75 486, 2005.

JUTURU, V., WU, J. C. Microbial xylanases: engineering, production and industrial applications. Biotechnology advances, v. 30 , n. 6, p. 1219-1227, 2012.

KLUCZEK-TURPEINEN, B. et al., Lignin degradation in a compost environment by the deuteromycete Paecilomyces inflatus. Applyed Microbiological Biotechnology, v. 61, p. 374-379, 2003.

KUDANGA, T., LE ROES-HILL, M. Laccase applications in biofuels production: current status and future prospects. Applied microbiology and biotechnology, v. 98, n. 15, p. 6525-6542, 2014.

KUHAD, R. C.; GUPTA, R.; SINGH, A. Microbial cellulases and their industrial applications. Enzyme research, v. 2011, 2011.

LEITNER, C. et al. Purification and characterization of a laccase from the white-rot fungus Trametes multicolor. In: Biotechnology for Fuels and Chemicals, p. 497-507, 2002.

LOERA, C.O. Laccases. Advances in Agricultural and Food Biotechnology, Cap.15, p.323-340, Editors: Ramón Gerardo Guevara-González and Irineo Torres-Pacheco, 2006.

LOTFY, W. A.; GHANEM, K. M.; EL-HELOW, E. R. Citric acid production by a novel Aspergillus niger isolate: I. Mutagenesis and cost reduction studies. Bioresource Technology, v.98, n.18, p. 3464-3469, 2007.

MADHAVI, V., LELE, S. S. Laccase: properties and applications. BioResources, v. 4, n. 4, p. 1694-1717, 2009.
MATA-GOMEZ, M. et al. A Novel tannase from the xerophilic fungus Aspergillus niger $\mathrm{GH} 1$. Journal of Microbiology and Biotechnology, v.19, n.9, p.987996, 2009.

MEKMOUCHE, Y. et al. Gram-scale production of a basidiomycetous laccase in Aspergillus niger. Journal of bioscience and bioengineering, v. 117, n. 1, p. 25-27, 2014.

MINUSSI, R. C., PASTORE, G. M.; DURÁN, N. Potential applications of laccase in the food industry. Trends in Food Science \& Technology, v. 13, n. 6, p. 205-216, 2002.

OLGA, V.K.S. et al.Purification and characterization of the constitutive form of laccase from basidiomycete Coriolus hirsutus and effect of inducers on laccase synthesis. Biotechnol. Appl. Biochem. v.28, p.47-54, 1998.

PATRO, K. R. et al. Development of new medium composition for en $\mathrm{d}$ production of L-asparaginase by Aspergillus f. Journal of Environmental Biology, v.35, p.295-300, 2014.

POINTING, S.B.; JONES, E. B. G. \& VRIJMOED, L. L. $P$. Optimization of laccase production by Pycnoporus sanguineus in submerged liquid culture. Mycologia, Lawrence, v. 92, p. 139-144, 2000.

POZDNYAKOVA, N.N. et al. Catalytic properties of yellow laccase from Pleurotus ostreatus D1. J. Mol. Catal, v. 30, p. 19-24, 2004.

SHEKHER, R. et al. Laccase: microbial sources, production, purification, and potential biotechnological applications. Enzyme research, p. 1-11, 2011.

SHIVANNA, G. B.; VENKATESWARAN, G. Phytase Production by Aspergillus niger CFR 335 and Aspergillus ficuum SGA 01 through Submerged and Solid-State Fermentation. The Scientific World Journal, ID 392615, p. 1-6, 2014.

SOUZA, C. G. M. et al., Production of laccase isoforms by Pleurutous pulmonaris in response to presence of phenolic and aromatic compounds. Journal Basic Microbiology, v.44, n.2, p.129 -136, 2004.

WARD, O. P. et al. Physiology and Biotechnology of Aspergillus. Advances in Applied Microbiology, v.58, p.1-75, 2005. 